OPEN ACCESS

Edited by:

Jun Wang,

University of Wisconsin-Madison,

United States

Reviewed by:

Youqi Zheng,

Xi'an Jiaotong University, China

Zhuo Li,

Sun Yat-sen University, China

Qian Zhang,

Harbin Engineering University, China

*Correspondence:

Tengfei Zhang

zhangtengfei@sjtu.edu.cn

Specialty section: This article was submitted to

Nuclear Energy,

a section of the journal

Frontiers in Energy Research

Received: 17 January 2020

Accepted: 11 February 2020

Published: 03 March 2020

Citation:

Zhang T, Liu X, Xiong J and Cheng X (2020) Comparisons of Reduced Moderation Small Modular Reactors With Heavy Water Coolant.

Front. Energy Res. 8:27.

doi: 10.3389/fenrg.2020.00027

\section{Comparisons of Reduced Moderation Small Modular Reactors With Heavy Water Coolant}

\author{
Tengfei Zhang ${ }^{1 *}$, Xiaojing Liu ${ }^{1}$, Jinbiao Xiong ${ }^{1}$ and Xu Cheng ${ }^{2}$ \\ ${ }^{1}$ School of Nuclear Science and Engineering, Shanghai Jiao Tong University, Shanghai, China, ${ }^{2}$ Institute of Fusion and \\ Nuclear Technology, Karlsruhe Institute of Technology, Karlsruhe, Germany
}

This article presents the comparison of two reduced moderation small modular reactor concepts with heavy water coolant. Two reduced moderation small modular reactors, RMSMR-Th and RMSMR-MOX, are proposed for the sustainable utilization of nuclear resources. The design concepts are established on modifications of the well-experienced pressurized water reactor technology. Tightly packed lattice and heavy water coolant are employed to yield a hard neutron spectrum, which proved advantageous for increasing the conversion ratio, as well as lowering the burn-up reactivity swing between beginning of cycle and end of cycle. Thorium-uranium dioxide fuel and MOX fuel are compared using the same core arrangement, and the small modular reactor concept is adopted to reduce void coefficients. Radial blanket region and axial blanket region are adopted to enhance the fissile breeding, and a three-zone fuel configuration is adopted to flatten the power distribution. Core burn-up calculations were carried out to investigate the available cycle length, the conversion ratio, the power peaking factors, reactivity coefficients, etc. Light-water-based thermal-hydraulic models were employed to examine the safety features of the concepts. Numerical simulations indicate that both RMSMR-Th and RMSMR-MOX can sustain the power generation of $100 \mathrm{MWe}$ by 7 years without refueling. Compared with thorium-uranium dioxide fuel, MOX fuel is helpful in reducing the burn-up reactivity swing, increasing the conversion ratio, and increasing the minimum departure from nuclear boiling ratio value. However, the positive void coefficient becomes a problem making RMSMR-MOX less attractive than the RMSMR-Th concept.

Keywords: nuclear reactor design, reduced moderation, small modular reactor, heavy water coolant, epithermalto-fast neutron spectrum

\section{INTRODUCTION}

Over the years, research interests in liquid metal fast reactors (LMFRs) have kept increasing because of their prominent features of uranium resources utilization and nuclear waste reduction. Due to the fast neutron spectra, the fission-to-capture ratio produced per fission in LMFRs is increased (Yang, 2012), leading to more fissile nuclear material production. A fast neutron spectrum can be achieved by employing coolants with small scattering cross sections (XSs) such as sodium, lead, or lead-bismuth eutectic (LBE). Although in recent years the fast reactor technology has progressed extensively, problems in the mainstream fast reactors (i.e., LMFRs) are still delaying the rapid spread of this technology. For example, the sodium coolant reacts with water and air, which requires caution while handling sodium to avoid leakage from the reactor. In contrast, lead and LBE are stable from the chemical perspective, but LBE produces non-negligible amount of the radiotoxic isotope ${ }^{210} \mathrm{Po}$. 
Moreover, both lead and $\mathrm{LBE}$ are corrosive, posing risks to structural materials (Cacuci, 2010).

Besides, lowering the moderator quantity by reducing the moderator-to-fuel ratio (MFR) is also beneficial in achieving a hard neutron spectrum, such as using a tightly packed fuel pins layout (tight lattice). Therefore, the reduced-moderation watercooled reactor was proposed (Okubo et al., 2003; Lindley et al., 2014), aiming for two design targets: an over-unity conversion ratio (CR) and maintaining negative void coefficients (VCs) during the whole cycle. It was found that boiling water reactor loaded with triangular lattices to reduce the coolant volume ratio effectively increases the CR, and a proper design of the core can sustain a whole-cycle negative VC. A pan-like short configuration is generally preferred to increase the axial neutron leakage by which to reduce the $\mathrm{VC}$, and radial and axial blanket regions were employed to increase the CR. Aside from employing boiling water and tightening the lattice configuration, the neutron spectrum hardening is also achievable by using heavy water $\left(\mathrm{D}_{2} \mathrm{O}\right)$. Although $\mathrm{D}_{2} \mathrm{O}$ is more expensive than light water $\left(\mathrm{H}_{2} \mathrm{O}\right)$ and produces radioactive products (tritium) by irradiation, the elastic scattering XS of deuterium is $1 / 5$ that of hydrogen. Consequently, a $\mathrm{D}_{2} \mathrm{O}$-cooled nuclear reactor with a small coolant volume ratio significantly hardens the neutron spectrum. The potential of this concept is two-fold: $\mathrm{D}_{2} \mathrm{O}$ is neither chemically active nor corrosive (as for liquid metal coolants); its similar thermal-physical properties as $\mathrm{H}_{2} \mathrm{O}$ enable the use of wellestablished LWR techniques as the nuclear industry has already accumulated extensive experience in maintaining and operating water-cooled reactors.

A few nuclear reactor concepts have been proposed based on the heavy water coolant. As an example, Hiruta and Youinou (2012, 2013a,b) at Idaho National Laboratory conducted analysis of tightly packed $\mathrm{D}_{2} \mathrm{O}$ high-conversion PWRs to shoot for near-breeder or break-even reactor concepts with negative whole-cycle void reactivity. The study was performed based on hexagonal MOX fuel assemblies and revealed important mechanisms such as the relation between MFRs and spectrum hardening, influences of blankets to the breeding effect and the coolant VC, and so on. In previous research, we undertook the conceptual design of a reduced moderation heavy water cooled reactor using thorium-uranium dioxide fuel (Zhang et al., 2019). The concept results in an epithermal-to-fast neutron spectrum and 7 years' operation time with $100-\mathrm{MWe}$ power output. It indicated better utilization of nuclear resources based on the wellexperienced water reactor technology. Besides, the epithermalto-fast neutron spectrum will suppress the production of minor actinides compared to a thermal spectrum, which lowers the waste management pressure and the radiotoxicity hazard of minor actinides. It was pointed out that in a thorium nuclear reactor ${ }^{232} \mathrm{U}$ emits high-energy gamma ray that brings risks to the ${ }^{232} \mathrm{Th} /{ }^{233} \mathrm{U}$ recycling compared to the plutonium nuclear reactor, and the reduced plutonium production is beneficial to the spent fuel proliferation resistance. ${ }^{232} \mathrm{U}$ poses a radiation hazard for terrorists who would extract the uranium due to the 2.6-MeV gamma decay of its decay daughter, ${ }^{208} \mathrm{Tl}$; only $1 \mathrm{ppm}$ of ${ }^{232} \mathrm{U} / \mathrm{U}$ poses a similar risk as reactor-grade $\mathrm{Pu}$ (Zhang et al., 2019). However, the ${ }^{233} \mathrm{U}$-based fuel appears less practical than ${ }^{235} \mathrm{U}$ - or ${ }^{239} \mathrm{Pu}$-based ones (i.e., $\mathrm{UO}_{2}$ or MOX fuels), because the ${ }^{233} \mathrm{U}$ isotope does not exist in nature. It is worthwhile to exploit the possibility of more conventional nuclear fuel types. Therefore, in this research, we substitute the fuel type of RMSMR with MOX and offer comparisons of neutronics and thermalhydraulics features between MOX-fueled concept and thoriumuranium-fueled concept.

The remainder of this article is organized as follows. As the foundation of this research, in Description of Reactor Core, the three-dimensional RMSMR core design is discussed in retrospect. In Comparisons Between RMSMR-TH and RMSMR$M O X$, the RMSMR employing MOX fuel (RMSMR-MOX) is introduced and compared with the RMSMR-Th. The Conclusions gives conclusions and points to possible directions for future research.

\section{DESCRIPTION OF REACTOR CORE}

Like most small modular reactors, the RMSMR is designed to be applicable for the deployment in outlying areas such as mountain area and islands. A $100-$ MWe power rating with a longer than 5 years' operational period is anticipated here to meet the power demand for the practical industrial application of interest, and the small core size has the expected advantages of serial production and incremental deployment, as well as the match to electric grid sitting opportunities. In addition, the fuel conversion phenomenon caused by the epithermal-to-fast neutron spectrum in RMSMR renders longer operational time than current PWR-type SMRs.

The RMSMR design is established within the framework of the traditional PWR technology, that is, adopting a $17 \times$ 17 PWR assembly with a pin pitch of $1.26 \mathrm{~cm}$. The MFR is evaluated as the ratio of the coolant volume to the fuel volume inside each square pin cell, and an MFR of 0.65 was selected considering the trade-off between maximizing $\mathrm{CR}$, as well as reducing the VC. Figure 1 shows the twodimensional schematic view of the fuel assembly employed in the RMSMR.

Two fuel types are considered in this research, that is, ${ }^{233} \mathrm{U}-$ $\mathrm{ThO}_{2}$ fuel and MOX fuel. The reactor concepts are named RMSMR-Th and RMSMR-MOX, respectively. In both concepts,

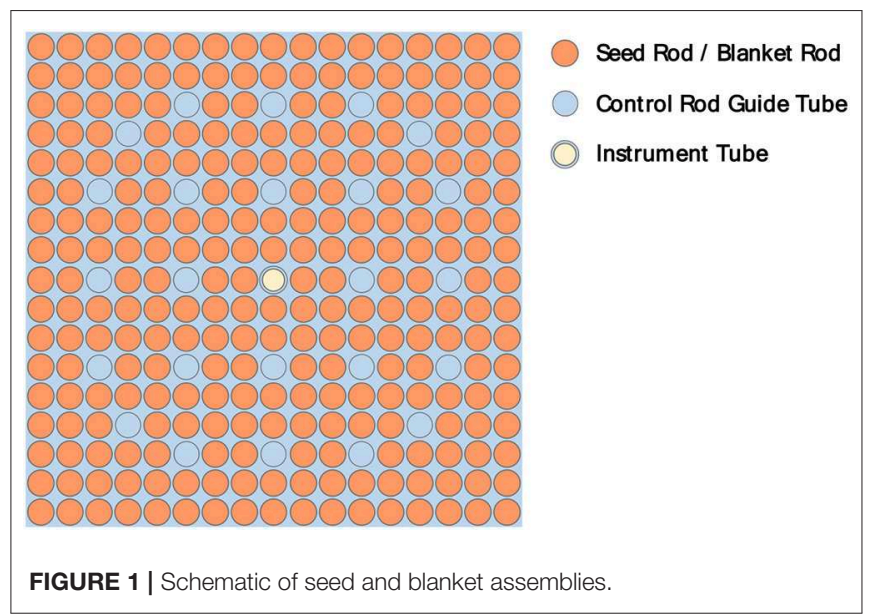


the flattening of the radial power distribution is achieved by the three-zone out-in assembly configuration. To achieve the expected 7-year operation period, the fissile isotope enrichments of RMSMR-Th seed assemblies are 11.0, 12.5, and 14.0\%, as shown in Figure 2. In contrast, the molecular fractions of $\mathrm{PuO}_{2}$ [weapon-grade plutonium dioxide (Bortot et al., 2011)] in RMSMR-MOX seed assemblies are 13.0, 14.0, and 15.0\%, respectively. The blanket assemblies are designed to employ the same geometry as seed assemblies loaded with $\mathrm{ThO}_{2}$ or depleted uranium (Bortot et al., 2011). To increase the reactor's CR, radial and axial blankets are adopted, as illustrated in Figure 3. The core is loaded with a seed fuel region of $100-\mathrm{cm}$ in the middle of the core, and $10-\mathrm{cm}$ blanket regions at the top and the bottom to enhance the leakage effect upon coolant voiding whereby achieving the negative VC. A $40-\mathrm{cm}$ upper plenum is also considered to account for the fission gas release during irradiation. The excess reactivity could be suppressed by $\mathrm{B}_{4} \mathrm{C}$ control rods with $90 \%$ enrichment of ${ }^{10} \mathrm{~B}$ (Zhang et al., 2019).

\section{COMPARISONS BETWEEN RMSMR-TH AND RMSMR-MOX}

Figure 4 presents $k_{\text {eff }}$ and CR variations vs. time modeled with OpenMC. Calculations are performed using 250 particle histories among which 100 are set at inactive, with 100,000 particles per history. The over-unity CR of RMSMR-Th and RMSMR-MOX at the beginning of cycle incurred the increase of $k_{\text {eff }}$. The $k_{\text {eff }}$ and the CR values for both RMSMR-Th and RMSMR-MOX begin to drop at the second year because of the counteraction between the accumulation of fission products and the fissile breeding. Both concepts can sustain the operation period of 7 years. Additionally, it can be observed that the RMSMRMOX outperforms RMSMR-Th in terms of the reactor control, because the reactivity swing during the cycle is smaller. However, the slightly larger reactivity swing of RMSMR-Th can also be controlled by control rods or burnable poisons. Figure 5 compares the neutron spectrum of RMSMR-Th, RMSMR-MOX,

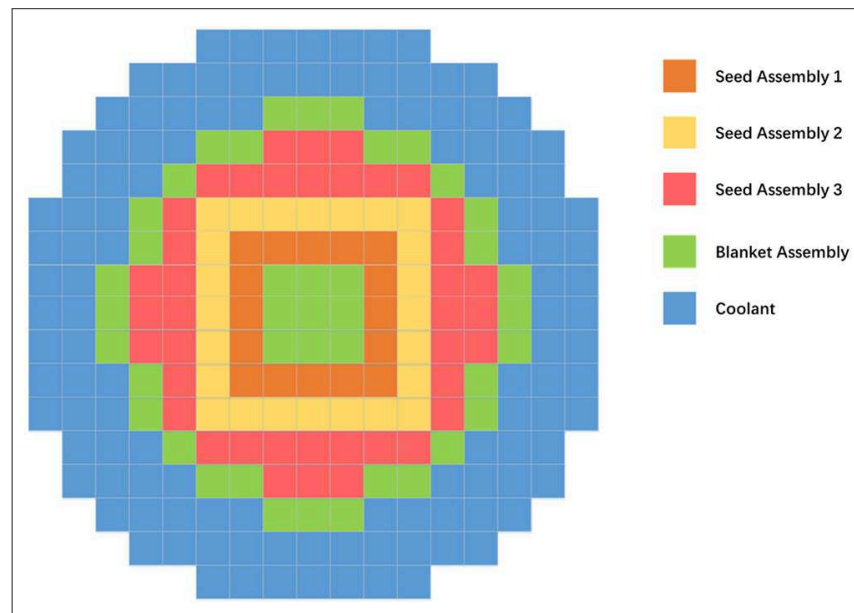

FIGURE 2 | Radial schematic view of RMSMR-Th.
SFR, and PWR. It can be observed that the use of $\mathrm{D}_{2} \mathrm{O}$ shifts the neutron spectrum to epithermal-to-fast energy range, and the hardening of neutron spectrum with MOX fuel appears more pronounced than with thorium-uranium-based fuel. Therefore, the CR of RMSMR-MOX is slightly higher than that of RMSMRTh, for example, 0.88 vs. 0.86 at End of Cycle (EOC). Because of the larger CR, the burn-up reactivity swing of RMSMR-MOX is smaller than that of RMSMR-Th. RMSMR-MOX has a reactivity change of $+1 \$$ during the whole operational period, which facilitates the reactivity control. In comparison, the reactivity change of RMSMR-Th is $-3.7 \$$.

The blanket assemblies cause a local power dip in the core center (i.e., a high-power peaking factor) at Beginning of Cycle (BOC), whereas with fuel conversion the peaking factor rapidly decreases with time, as shown in Table 1. Some important design parameters of RMSMRs are tabulated in Table 2 . The

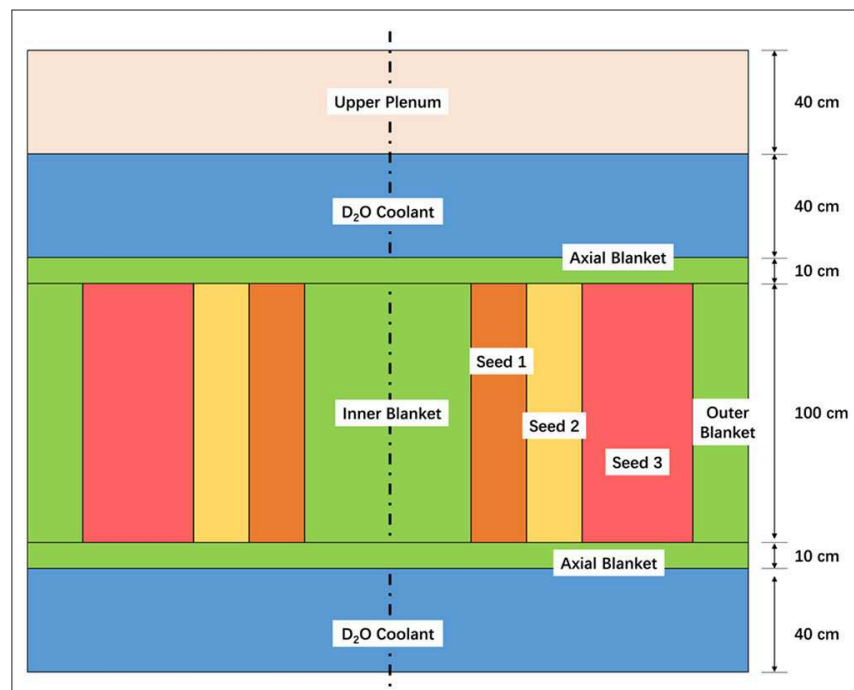

FIGURE 3 | Axial schematic view of RMSMR-Th.

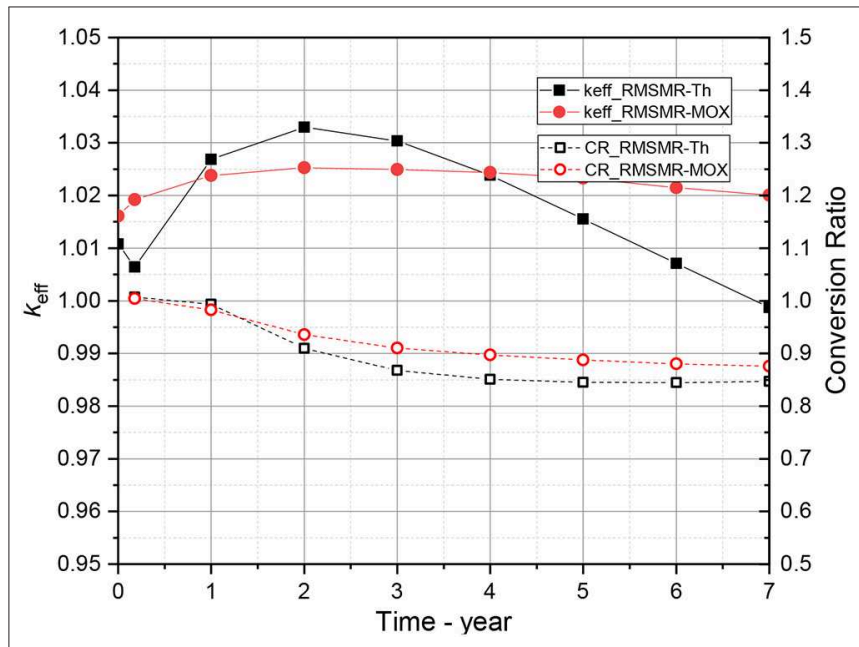

FIGURE $4 \mid k_{\text {eff }}$ and CR variations of RMSMR-Th and RMSMR-MOX. 


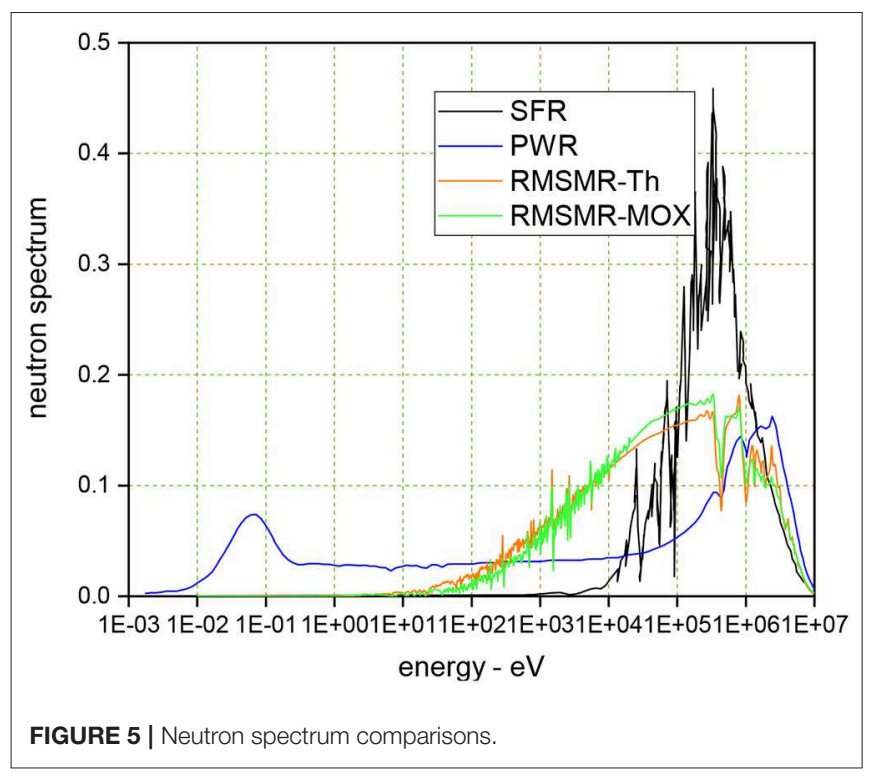

TABLE 1 | Power peaking factors.

\begin{tabular}{llllll}
\hline & \multicolumn{2}{c}{ RMSMR-Th } & & \multicolumn{2}{c}{ RMSMR-MOX } \\
\cline { 2 - 3 } & Radial & Axial & & Radial & Axial \\
\hline BOC & 1.90 & 1.44 & & 1.84 & 1.35 \\
MOC & 1.43 & 1.07 & & 1.60 & 1.17 \\
EOC & 1.40 & 1.15 & & 1.53 & 1.14 \\
\hline
\end{tabular}

power outputs of the two concepts are both $300 \mathrm{MWth} / 100$ MWe, and the operating pressures are both $15.5 \mathrm{MPa}$. The coolant temperatures are referenced from commercial PWRs, with the inlet/outlet temperatures of $285^{\circ} \mathrm{C} / 315^{\circ} \mathrm{C}$. The coolant mass flow rate is set at around $1,960 \mathrm{~kg} / \mathrm{s}$ for both RMSMR. Resultantly, pressure drops are estimated to be 4.9 and $5.9 \mathrm{kPa}$, respectively, for RMSMR-Th and RMSMR-MOX based on the Blasius correlation.

It should also be noted that the tight lattice core tends to reduce the critical heat flux and increase the pressure drop, which brings concerns to the thermal-hydraulic safety. To look into the thermal-hydraulics features, the $\mathrm{W}-3$ formula widely used for PWRs is adopted to estimate the minimum departure from nuclear boiling ratio (mDNBR), thanks to the similar thermal properties of $\mathrm{D}_{2} \mathrm{O}$ and $\mathrm{H}_{2} \mathrm{O}$. Based on the power peaking factors in Table 1, total powers of hot fuel pins are $33.7 \mathrm{~kW}$ for RMSMR-Th and $32.7 \mathrm{~kW}$ for RMSMR-MOX. Correspondingly, enthalpy rises are $362.7 \mathrm{~kJ} / \mathrm{kg}$ and $333.4 \mathrm{~kJ} / \mathrm{kg}$, respectively, based on the conservative uniform coolant flow distribution. The slight differences in thermal-hydraulic parameters between RMSMR-Th and RMSMR-MOX are caused by different pin power distributions. Eventually, the calculation with the $\mathrm{W}-3$ formula yielded mDNBR values of 2.84 and 3.22 for RMSMRTh and RMSMR-MOX, respectively. As indicated, the thermalhydraulics safety margin for RMSMR-MOX is larger than that for RMSMR-Th.
TABLE 2 | Basic reactor design parameters of RMSMR.

\begin{tabular}{|c|c|c|}
\hline Items & RMSMR-Th & RMSMR-MOX \\
\hline $\begin{array}{l}\text { Thermal power/electric power } \\
\text { (MW) }\end{array}$ & $300 / 100$ & \\
\hline Pressure (MPa) & 15.5 & \\
\hline Pressure drop (kPa) & 4.9 & 5.9 \\
\hline Core lifetime (years) & 7 & \\
\hline Core height (cm) & 120 & \\
\hline Equivalent diameter (cm) & 364 & \\
\hline Number of seed fuel assemblies & 80 & \\
\hline Number of blanket assemblies & 41 & \\
\hline Coolant type & Heavy water $\left(D_{2}\right.$ & \\
\hline Fuel type & ${ }^{233} \mathrm{U} \_232 \mathrm{Th}$ dioxide & MOX \\
\hline Enrichment (\%) & $\begin{array}{l}\text { 11.0/12.5/14.0, } 3 \text { radial } \\
\text { zones }\end{array}$ & $\begin{array}{l}\text { 13.0/15.0/18.0, } \\
3 \text { radial zones }\end{array}$ \\
\hline Core ${ }^{233} \mathrm{U} /{ }^{239} \mathrm{Pu}$ inventory (tHM) & 1.5 & 2.3 \\
\hline Core $^{232} \mathrm{Th} / 238 \mathrm{U}$ inventory (tHM) & 12.4 & 20.0 \\
\hline $\begin{array}{l}\text { Average discharged burn-up } \\
\text { (MWd/tHM) }\end{array}$ & 55.2 & 32.4 \\
\hline $\begin{array}{l}\text { Core inlet/outlet temperatures } \\
\left({ }^{\circ} \mathrm{C}\right)\end{array}$ & $285 / 315$ & \\
\hline Coolant flow rate $(\mathrm{kg} / \mathrm{s})$ & $\approx 1,960$ & \\
\hline Power density $\left(\mathrm{W} / \mathrm{cm}^{3}\right)$ & $\approx 82$ & \\
\hline \multicolumn{3}{|l|}{ Assembly geometry } \\
\hline Fuel pellet diameter (cm) & 1.0455 & \\
\hline Fuel pin diameter (cm) & 1.1455 & \\
\hline Number of pins/assembly & $264(17 \times 17)$ & \\
\hline Moderator to fuel ratio & 0.65 & \\
\hline
\end{tabular}

TABLE 3 | Reactor safety characteristics of RMSMR.

\begin{tabular}{|c|c|c|}
\hline Items & RMSMR-Th & RMSMR-MOX \\
\hline \multicolumn{3}{|l|}{ Effective delayed neutron fraction $(\mathrm{pcm})$} \\
\hline $\mathrm{BOC}$ & $319.0 \pm 21.0$ & $372.0 \pm 31.0$ \\
\hline EOC & $307.0 \pm 23.0$ & $353.0 \pm 30.0$ \\
\hline \multicolumn{3}{|l|}{ Prompt neutron generation time $(\mu \mathrm{S})$} \\
\hline $\mathrm{BOC}$ & $12.1 \pm 0.7$ & $168.2 \pm 1.0$ \\
\hline EOC & $174.4 \pm 2.7$ & $250.5 \pm 1.8$ \\
\hline $\mathrm{FTC}(\mathrm{pcm} / \mathrm{K})$ & $-6.4 \pm 0.1$ & $-3.6 \pm 0.2$ \\
\hline Coolant temperature coefficient (pcm/K) & $-22.7 \pm 0.1$ & $-3.4 \pm 0.3$ \\
\hline \multicolumn{3}{|l|}{ Void reactivity coefficient (pcm/\%void) } \\
\hline $\mathrm{BOC}$ & $-211.7 \pm 0.4$ & $+736.5 \pm 0.6$ \\
\hline EOC & $-105.8 \pm 0.4$ & $+487.9 \pm 0.5$ \\
\hline
\end{tabular}

Last but not least, key reactivity coefficients are evaluated, that is, the VC, the fuel temperature coefficient (FTC), and the coolant temperature coefficient (CTC). To obtain the VC, a $5 \%$ reduction in the coolant density is considered to simulate a 5\% coolant voiding. The FTC is evaluated based on the reactivity/Kelvin between 900 and $600 \mathrm{~K}$ fuel temperatures. The CTC is computed as the reactivity/Kelvin between 600 and $300 \mathrm{~K}$ coolant temperatures. Table 3 compares reactor safety characteristics of RMSMR-Th and RMSMR-MOX. It can be 
observed that incorporations of ${ }^{233} \mathrm{U}$ and ${ }^{239} \mathrm{Pu}$ lead to smaller effective delayed neutron fractions $\left(\beta_{\text {eff }}\right)$ than a conventional ${ }^{235} \mathrm{U}$-fueled reactor (Kazimi et al., 1999), although the MOX fuel

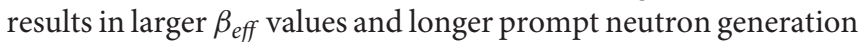
time than thorium-uranium-based fuel. The smaller $\beta_{\text {eff }}$ of the RMSMR-Th than the RMSMR-MOX implies an issue upon reactivity-induced transients, but can be somewhat mitigated by the faster Doppler feedback response because the harder neutron spectrum yields much shorter neutron lifetime. The FTC and CTC values of RMSMR-MOX are smaller than those of RMSMRTh, but still within the required negative range. One crucial problem with MOX fuel would be the increased void reactivity coefficient, which is remarkably positive throughout the whole operation cycle, with a value of $+736 \pm 0.6 \mathrm{pcm} / \%$ void at BOC. To tackle with this problem, several measures can possibly be taken, such as compaction of the core to enhance the neutron leakage upon coolant voiding, or increasing the MFR to soften the neutron spectrum, and so on. Also, it is noted in Hibi et al. (2001) work that a triangular lattice configuration with heterogeneous internal blanket yields an over-unity $\mathrm{CR}$ with negative void reactivity coefficient.

\section{CONCLUSIONS}

This article presents comparisons of two reduced moderation small modular reactors, RMSMR-Th and RMSMR-MOX. The design concepts are established on modifications of the pressurized water reactor technology. For increasing the CR for better utilization of uranium resources and for

\section{REFERENCES}

Bortot, S., Moisseytsev, A., Sienickib, J. J., and Artioli, C. (2011). Core design investigation for a SUPERSTAR small modular lead-cooled fast reactor demonstrator. Nuclear Eng. Design. 241, 3021-3031. doi: 10.1016/j.nucengdes.2011.04.012

Cacuci, D. G. (ed.). (2010). Handbook of Nuclear Engineering: Vol. 1: Nuclear Engineering Fundamentals; Vol. 2: Reactor Design; Vol. 3: Reactor Analysis; Vol. 4: Reactors of Generations III and IV; Vol. 5: Fuel Cycles, Decommissioning, Waste Disposal and Safeguards. Springer Science \& Business Media

Hibi, K., Shimadab, S., Okubob, T., Iwamurab, T., and Wada, S. (2001). Conceptual designing of reduced-moderation water reactor with heavy water coolant. Nuclear Eng. Design 210, 9-19. doi: 10.1016/S0029-5493(01)00420-4

Hiruta, H., and Youinou, G. (2012). Preliminary Neutronics Design and Analysis of $\mathrm{D}_{2} \mathrm{O}$ Cooled High Conversion PWRs. Idaho National Laboratory. doi: 10.2172/1060965

Hiruta, H., and Youinou, G. (2013a). Preliminary Neutronic Study of $\mathrm{D}_{2} \mathrm{O}$-cooled High Conversion PWRs. Idaho National Laboratory.

Hiruta, H., and Youinou, G. (2013b). Investigation of the Performance of $\mathrm{D}_{2} \mathrm{O}$ Cooled High-Conversion Reactors for Fuel Cycle Calculations. Idaho National Laboratory. doi: 10.2172/1115609

Kazimi, M. S., Czerwinski, K. R., Driscoll, M. J., Hejzla, P., and Meyer, J. E. (1999). On the Use of Thorium in Light Water Reactors. Department of Nuclear Engineering, MIT, MIT-NFCTR-016. reducing the burn-up reactivity swing to simplify the reactivity control, reduced-moderation lattice and heavy water coolant are employed. Thorium-uranium dioxide fuel and MOX fuel are compared using the same core arrangement. Compared with thorium-uranium dioxide fuel, MOX fuel reduces the burn-up reactivity swing and increases the $\mathrm{CR}$ and the $\mathrm{MDNBR}$ value while preserving negative FTC and CTC. However, MOX fuel incurs the coolant VC to become positive. This becomes a serious problem, making the current RMSMR-MOX less attractive than the RMSMR-Th concept. Further studies are required to optimize the core size, the MFR, and the layout of assemblies in order to reduce the VC of RMSMR-MOX.

\section{DATA AVAILABILITY STATEMENT}

The datasets generated for this study are available on request to the corresponding author.

\section{AUTHOR CONTRIBUTIONS}

All authors listed have made a substantial, direct and intellectual contribution to the work, and approved it for publication.

\section{FUNDING}

This research was supported by the National Natural Science Foundation of China (Grant Nos. 11805122 and 11922505) and Startup Fund for Youngman Research at SJTU.

Lindley, B. A., Franceschini, F., and Parks, G. T. (2014). The closed thoriumtransuranic fuel cycle in reduced-moderation PWRs and BWRs. Ann. Nuclear Energy 63, 241-254. doi: 10.1016/j.anucene.2013.07.052

Okubo, T., Takamichi, I., Renzo, T., Toyoaki, Y., and Hiroyuki, O. (2003). “Design study on reduced-moderation water reactor (RMWR) core for plutonium multiple recycling," Proceedings of GENES4/ANP2003 (Kyoto), 1145.

Yang, W. S. (2012). Fast reactor physics and computational methods. Nuclear Eng. Technol. 44, 177-198. doi: 10.5516/NET.01.2012.504

Zhang, T., Xiong, J., Liu X., Chai, X., Li, W., and Cheng, X. (2019) Conceptual design of an innovative reduced moderation thorium-fueled small modular reactor with heavy-water coolant. Int. J. Energy Res. 43, 8286-8298. doi: 10.1002/er.4827

Conflict of Interest: The authors declare that the research was conducted in the absence of any commercial or financial relationships that could be construed as a potential conflict of interest.

Copyright (c) 2020 Zhang, Liu, Xiong and Cheng. This is an open-access article distributed under the terms of the Creative Commons Attribution License (CC BY). The use, distribution or reproduction in other forums is permitted, provided the original author(s) and the copyright owner(s) are credited and that the original publication in this journal is cited, in accordance with accepted academic practice. No use, distribution or reproduction is permitted which does not comply with these terms. 